\title{
Strength Calculation of Stiffened Structures Taking Into Consideration Realistic Weld Imperfections
}

\author{
Christoph Stapelfeld ${ }^{1, a,{ }^{*}}$, Benjamin Launert ${ }^{1, b}$, Hartmut Pasternak ${ }^{1, c}$, \\ Nikolay Doynov ${ }^{2, \mathrm{~d}}$, Vesselin Michailov ${ }^{2, \mathrm{e}}$ \\ ${ }^{1}$ Chair of Steel and Timber Structures, Konrad-Wachsmann-Allee 2, Brandenburg University of \\ Technology, Cottbus, Germany \\ ${ }^{2}$ Chair of Joining and Welding Technology, Konrad-Wachsmann-Allee 17, Brandenburg \\ University of Technology, Cottbus, Germany \\ achristoph.stapelfeld@b-tu.de, benjamin.launert@b-tu.de, 'chartmut.pasternak@b-tu.de, \\ dnikolay.doynov@b-tu.de, ${ }^{\mathrm{e}}$ vesselin.michailov@b-tu.de
}

Keywords: Strength Calculation, Welding, Imperfections, Load Capacity, Stiffened Structures, Curved Structures, Hybrid Model

\begin{abstract}
The topic of this article is the application of an analytical numerical hybrid model for a realistic prediction of imperfections induced by welds. At the beginning, the analytical model, its physical basis as well as the physical interrelationships are explained. This is followed by the explanation of the coupling procedure between the analytical model and the numerical calculation. Afterwards, the coupled hybrid model is applied on the investigated stiffened curved structure for the determination of the weld imperfections. An ultimate load analysis gives information about the load carrying behavior under axial loading. The results are compared against the traditional approach using eigenmode-based imperfections. The comparison underlines the potential additional utilization of load bearing capacity by this new approach.
\end{abstract}

\section{Introduction}

The strength calculation of stiffened plates by the finite element method (FEM) has been part of the state of the art for a long time. Geometrical nonlinearities as well as the nonlinear material behavior are considered within the calculation. To simplify, both types of imperfections, geometrical and structural ones, are mostly combined in these strength calculations being considered as equivalent geometrical imperfections. Values for standard cases are included in EN 1993-1-5 in case of plated structures or slightly curved panels [1]. Because there are no specific rules for considering imperfections and its scaling in a load capacity calculation of stiffened curved panels they may be also assumed according to EN 1993-1-5 [2,3] as a first approach. However, it remains unclear to some extent how accurate these geometrical imperfections represent the actual residual stresses and deformations caused by welds, especially for more complex cases. The significance of numerical load capacity calculations could be increased enormously if these imperfections were known more exactly and could be considered directly during the computation.

Nowadays, the residual stresses and deformations can be determined by means of a thermomechanical FE simulation achieving quite realistic values. However, relevant structures and weld length are very large what leads to enormous calculation time and a huge demand of storage capacity [4]. Simplified numerical approaches are available and able to remedy this situation.

However, the application of these models partly demands more expertise than a conventional thermomechanical FE calculation [5] or the simplifications are so extensive that the weld imperfections calculated by the approach partially lose their validity [6]. In order to be able to take weld distortions and residual stresses directly into account in a load capacity calculation, 
fast but still sufficiently accurate procedures that, at the same time, are easy in their application are essential.

\section{The Coupled Analytical Numerical Hybrid Model}

The basic idea of the coupled analytical numerical hybrid model [7] is the linking of the major advantages of both, analytical and numerical procedures. On the one hand, the matchless very short calculation time of the analytical shrinkage force model and its simple application, and on the other hand the possibility to conduct a FE simulation to calculate stresses and distortions at any location of complex welded structures. According to this, all the determining factors on quality and quantity of weld imperfections are passed to an analytical calculation program, capturing the mathematical approach of the shrinkage force model. The output is a mechanical load and the point of action in longitudinal and transversal direction, equivalent to the heat effect of welding. The loads are then applied to the FE model of the weld structure and the distortions and stresses are calculated by a nonlinear elastic calculation. The influence of the weld sequence on the arising weld imperfections is captured by a back coupling. The numerically calculated stresses in the regarded weld caused from a previous weld are submitted to the analytical calculation. The results of the application of the hybrid model are subsequently superposed with additional fabrication tolerances followed by the load capacity calculation, Fig. 1.

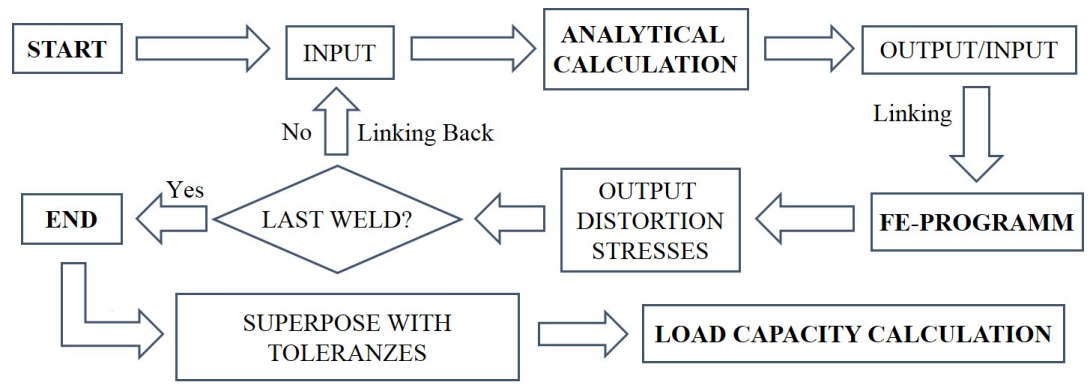

Figure 1: Scheme of the Load Capacity Calculation Taking Into Consideration Realistic Weld Imperfections.

Weld imperfections depend significantly on the maximum temperatures that every point perpendicular to the weld direction is exposed to and the stiffness of the structure. Equations for the calculation of the maximum temperatures were derived by Rykalin [8] constituting the basis of the shrinkage force model. For calculating a force alongside the weld, Okerblom [9] considered the border case of a line source in a rigid thin plate and integrated the thermal strains over the zone of plastic deformations:

$$
F_{x}=v_{x} E=\int_{\varepsilon_{F}}^{2 \varepsilon_{F}} 0,484 \frac{\alpha}{c \rho} \frac{q_{s}}{\varepsilon_{t h}} E d \varepsilon_{t h}=0,355 \frac{\alpha}{c \rho} q_{s} E,
$$

with $v_{\mathrm{x}}$, the shrinkage volume per unit length, $\varepsilon_{\mathrm{F}}$, the yield point, $\alpha$, the thermal expansion coefficient, c, the specific heat capacity, $\rho$, the density, $\mathrm{q}_{\mathrm{s}}$, the heat input per unit length, $\varepsilon_{\mathrm{th}}$, the thermal strains and E, the Young's modulus. Kuzminov [10] enlarged the application area as well as increased the accuracy of the analytic approach significantly by including the second border case of a point source on a semi-infinite body by means of an influencing factor $\mathrm{K}_{\chi \delta}$, mostly depending on the plate thicknesses and the heat exchange. Furthermore, the model considers the finite stiffness of the structure, $K_{k}$ and the effect of existing stresses in the weld, $\mathrm{K}_{\sigma}$ :

$$
F_{x}=0,355 \frac{\alpha}{c \rho} q_{s} E K_{\chi \delta} K_{k} K_{\sigma} .
$$


The longitudinal shrinkage force $F_{x}$ is proportional to the width of the plastic zone:

$$
b_{P Z}=\frac{F_{x}}{\varepsilon_{m} E \delta} .
$$

Here, $\varepsilon_{\mathrm{m}}$ is the averaged yield strain and $\delta$ is the plate thickness. The transversal shrinkage caused by welds depends on further effects like heating through the thickness, stiffening cross beams, the effect of longitudinal strains, the degree of excessive heat as well as the effect of forced heat exchange $[7,10]$. Both, the longitudinal and the transversal shrinkage force have an appropriate point of action being equivalent to the centre of the plastic zone. They are significantly influenced by the material and its properties as well as the heat input per unit length and the plate thickness. Depending on the points of action, $\mathrm{z}_{\mathrm{c}}$, an equivalent linear strain distribution over the plate thickness can be calculated. Considering the point of origin in the centre of gravity of the plates cross section, the strain distribution $\varepsilon_{\mathrm{z}}$ follows as:

$$
\varepsilon(z)=\varepsilon_{m}+\frac{12 \varepsilon_{m} Z_{c}}{\delta^{2}} Z
$$

The calculated linear strain distributions over the plate thickness are now applied to the analytically calculated width of the plastic zone in the FE model of the welded structure. In the case of shell elements, each integration point is loaded with the strains according to eq. 4 . The linking by means of stresses requires the consideration of the Poisson's ratio, eq. 5. The procedure is already validated and verified with Ansys ${ }^{\circledR}$, LS Dyna ${ }^{\circledR}$, Sysweld ${ }^{\circledR}$ and Abaqus ${ }^{\circledR}$.

$$
\sigma_{x, y}=\frac{\varepsilon_{x, y} E+\varepsilon_{y, x} E v}{1-v^{2}}
$$

Previous comparisons of the results of the analytical numerical hybrid model with experimental data have already shown very good agreement [4,7]. The field of application covers different steel grades, several types of joints and the established welding techniques. Currently, the largest calculated structure was a deck section from ship building with 90 welds [7]. The CPU calculation time using a customary computer was approximately $30 \mathrm{~min}$ and it took about $30 \mathrm{~h}$ for preparing the CAD model and creating the FE mesh. Compared with a conventional thermomechanical simulation the calculation time saving using this new approach was more than $99 \%[4,7]$.

\section{The Finite Element Model of the Curved Stiffened Structure}

For the application of the hybrid model and a subsequent load capacity calculation a panel similar to the panels of the Lyon Confluence footbridge in France, introduced in [2], was chosen, Fig 2. For defining the boundary conditions, a cylindrical coordinate system was created. The four edges of the panel are simply supported, $u_{R}=0$. To restrain any movement or rotation of the structure, two nodes in the middle of the curved edges are fixed alongside $\theta$ and one node in the middle of the panel is fixed in the direction of the $\mathrm{z}$ coordinate. The steel grade is S355. Correspondingly, the Young's modulus is $\mathrm{E}=210 \mathrm{GPa}$, the Poisson's ratio is $v=0.3$ and the yield strength is $\sigma_{\mathrm{F}}=355 \mathrm{MPa}$. For the GMNIA as well as the load capacity calculation with the consideration of realistic weld imperfections a slope of E/100 and an ultimate stress of $470 \mathrm{MPa}$ was assigned. The structure is discretized with four-node shell elements (S4R in Abaqus ${ }^{\circledR}$ ) with three integration points over the elements thickness. A quite fine mesh with an approximated element edge length of $30 \mathrm{~mm}$ is used. 


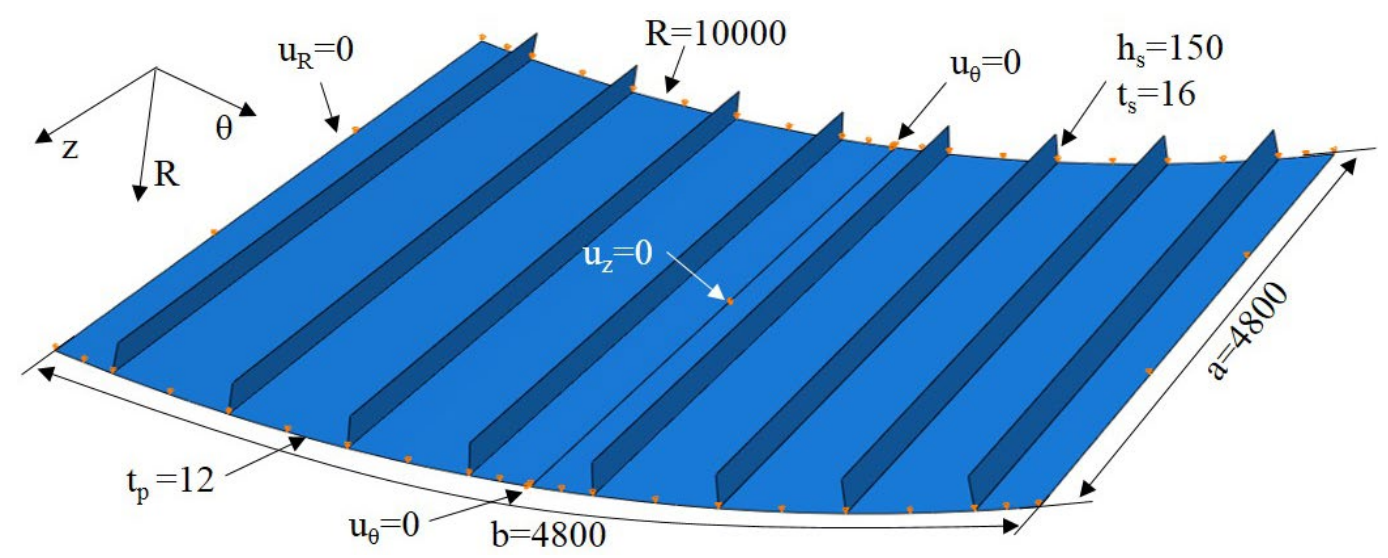

Figure 2: Geometrical Properties in mm and Boundary Conditions of the Curved Panel.

Considering the different plate thicknesses, the panel and the stiffeners are loaded with different shell edge loads targeting a homogeneous axial pressure, Fig 3(a). For the verification of the loading as well as the boundary conditions, the curvature of the plate was removed and a load capacity calculation was carried out. The numerically calculated plastic normal force was then compared with the analytical solution: $F=\sigma_{F} A=27.26 \mathrm{MN}$. For the determination of the lowest ultimate load, several load deformation calculations were executed considering different buckle modes as well as combinations of them. As a result, it turned out that the imperfection according to the first buckle mode, Fig 3(b), leads to the lowest load capacity.

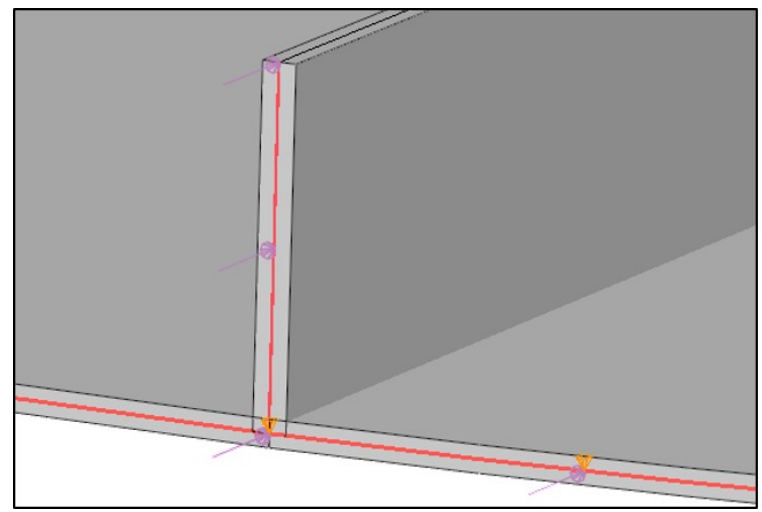

(a)

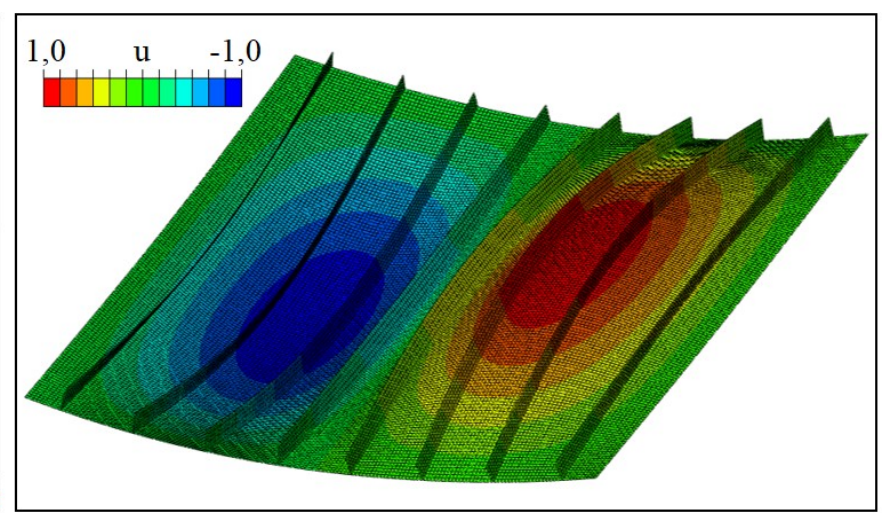

(b)

Figure 3: Loading Condition (a), and the First Buckle Mode (b).

\section{Application of the Hybrid Model for Calculating Weld Imperfections and Results of a Subsequent Load Capacity Analysis}

The requirements for the calculation of the mechanical loads with the analytical shrinkage force model are information about the type of joint and its dimensions, the material data as well as the welding technique and the welding parameters. Here, the initial assumption is made that the stiffeners are only welded one sided. The material data correspond to the material data of the steel S355J2. The weld technique is conventional MAG-welding with welding parameters targeting a fillet weld with a design throat thickness of $7 \mathrm{~mm}$, which resulted in a heat input per unit length of $\mathrm{q}_{\mathrm{s}}=2400 \mathrm{~J} / \mathrm{mm}$. In this example case, the linking between the analytical model and the numerical approach was done by initial stresses, Table 1.

Table 1: Analytically Calculated Stresses for the Numerical Calculation of Weld Imperfections.

\begin{tabular}{|c|c|c|c|c|c|c|}
\hline & \multicolumn{3}{|c|}{ Curved Panel } & \multicolumn{3}{|c|}{ Stiffener } \\
\hline $\begin{array}{l}\text { Location of the Three Integration Points } \\
\text { Width of Plastic Zone } b_{n z} \text { [mm] }\end{array}$ & Upper & $\begin{array}{c}\text { Middle } \\
29.1\end{array}$ & Lower & Upper & $\begin{array}{l}\text { Middle } \\
29.1\end{array}$ & Lower \\
\hline Stresses in Weld Direction $\sigma_{\mathrm{z}}[\mathrm{MPa}]$ & 849.6 & 597.4 & 345.2 & 807.7 & 593.8 & 379 \\
\hline Stresses Transversal to the Weld $\sigma[\mathrm{MPa}]$ & $\sigma_{\theta}=1313$ & $\sigma_{\theta}=801$ & $\sigma_{\theta}=289.5$ & $\sigma_{R}=1341$ & $\sigma_{R}=789$ & $\sigma_{R}=237$ \\
\hline
\end{tabular}


For the proper loading of the FE model, two sections were created at each weld, representing the idealized zone of plastic deformations. The width of the sections is specified by the width of the analytically calculated plastic zone. When creating the sections, the position of the welds on the outside of the stiffeners is considered, fig 4(a). The initial stresses in longitudinal and transversal direction are defined as "initial state” in Abaqus ${ }^{\circledR}$. Geometric nonlinear behavior is considered within the elastic calculation. The calculated deformation state indicates buckling of the curved panel in the positive z-direction and a tilt of the stiffeners towards the welds, Fig 4(b).

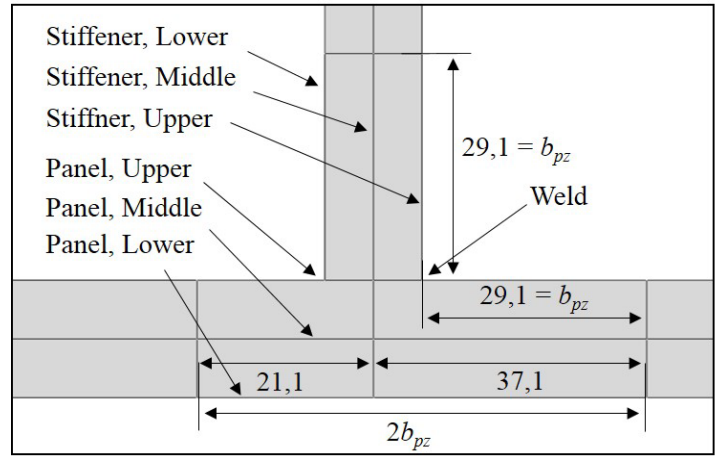

(a)

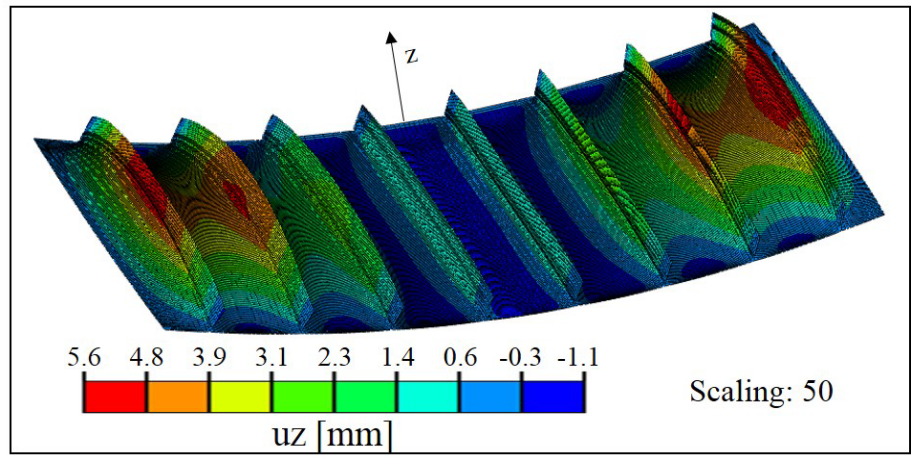

(b)

Figure 4: Assembly of the FE-Model in the Region of the Welds (a) and Out of Plane Deformations (b).

The ultimate load calculations were done assuming two kinds of imperfections. The first case is a combination of the geometrical and structural weld imperfections and manufacturing failures that were captured here by assuming an additional initial global buckle of b / $1000=4.8 \mathrm{~mm}$. In the second case, all imperfections in the structure are caused only by the eight welds representing the case of an ideal model prior to welding. The comparison of the ultimate loads with the results of the calculation considering the critical first buckling mode as initial imperfection has shown increased load capacities of $16 \%$ for case one and $31 \%$ for the second case, Fig 5.

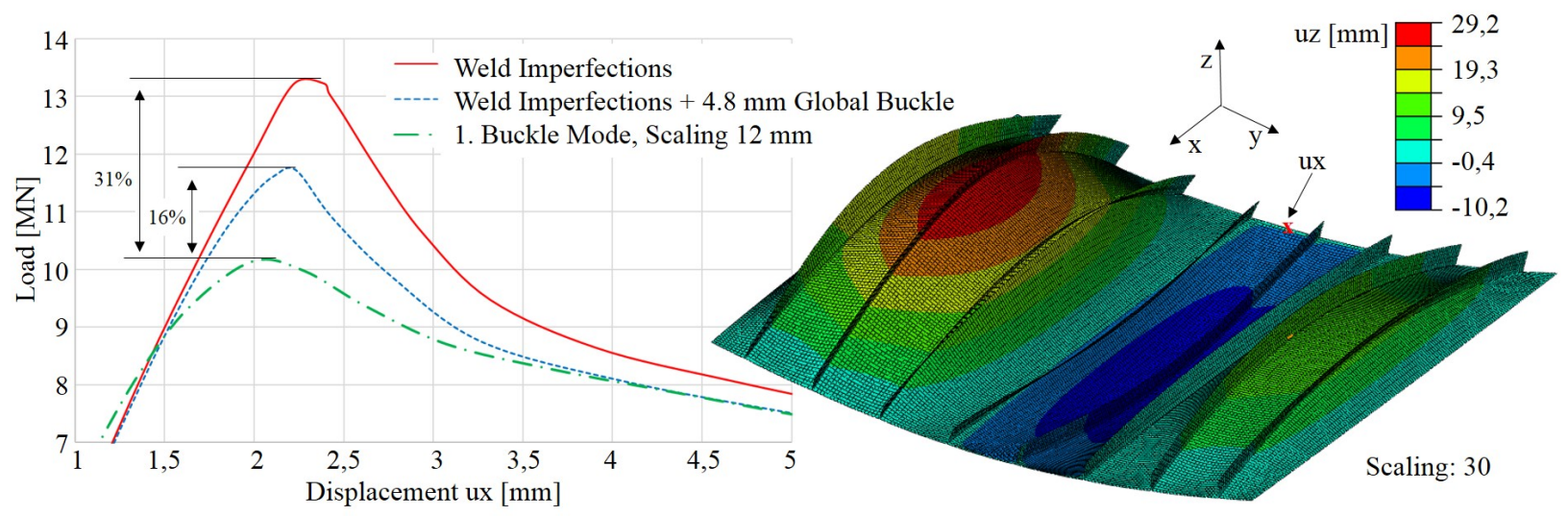

Figure 5: Load Displacement Curves and Corresponding Deformation State at Ultimate Load.

\section{Summary}

Numerous applications of the analytical numerical hybrid model for the calculation of weld imperfections indicate the significance of the results. In the case of consideration, the calculated longitudinal and transversal shrinkages as well as the out of plane deformations correlate well with known empirical values for one sided fillet welds. The use of calculated realistic weld imperfections instead of adequate imperfections in the load capacity calculation of the stiffened curved panel results in an increasing of the ultimate load in the range of $16 \%$ till $31 \%$. However, a general statement on the effects of weld imperfections in load capacity calculations cannot be given. The results depend on the geometry, the steel grade, the quantity and positions of the weld as well as the weld parameters. A realistic consideration of these parameters is only 
possible by an accurate approach of the type that has been presented in this article. However, the approach in combination with loading calculations has to be validated by means of more experimentally determined load displacement curves. These works are ongoing at the moment.

\section{Acknowledgements}

These works are part of the IGF project No. 19173 BR of the German Research Association for Steel Application (FOSTA). This project is kindly funded by the German Federal Ministry of Economic Affairs and Energy (BMWi) by the AiF (German Federation of Industrial Research Associations) as part of the program for support of the Industrial Cooperative Research (IGF) on the basis of a decision by the German Bundestag.

\section{References}

[1] Eurocode 3: Bemessung und Konstruktion von Stahlbauten (EN 1993-1-5). 2017

[2] K. L. Tran, C. Douthe, K. Sab, J. Dallot, L. Devaine, Buckling of Stiffened Curved Panels Under Uniform Axial Compression, Journal of Constructional Steel Research 103 (2014) 140147. https://doi.org/10.1016/j.jcsr.2014.07.004

[3] T. Manco, J. P. Martins, C. Rigueiro, L. S. da Silva, Numerical Analysis of Stiffened Curved Panels Under Compression, International Conference on Steel and Aluminium Structures, Hong Kong, China, 2016 1-12 (No. 28).

[4] V. Michailov, R. Ossenbrink, C. Stapelfeld, Anwendungsnahe Schweißsimulation komplexer Strukturen, DVS-Berichte, Band 282, DVS Media GmbH, Düsseldorf, 2010.

[5] Y. G. Duan, Y. Vincent, F. Boilot, J. B. Leblond, J. M. Bergheau, Prediction of welding residual distortions of large structures using a local/global approach, Journal of Mechanical Science and Technologie 21, 10 (2007) 1700-1706. https://doi.org/10.1007/BF03177397

[6] D. Thikomirov, B. Rietman, K. Kose, M. Makkink, Computing Welding Distortion: Comparison of Different Industrially Applicable Methods, SHEMET 11 (2008) 195-202.

[7] C. Stapelfeld, Vereinfachte Modelle zur Schweißverzugsberechnung, Dissertation, Shaker Verlag, Aachen, 2016.

[8] N. N. Rykalin, Berechnung von Wärmevorgängen beim Schweißen, VEB Verlag Technik, Berlin, 1957.

[9] N. O. Okerblom, Schweißspannungen in Metallkonstruktionen, VEB Carl Marhold Verlag, Halle (Saale), 1959.

[10]S. A. Kuzminov, Svarochnie deformazii sudovich korpusnich konstrukzii, Verlag Sudostroenie Leningrad, Leningrad, 1974. 